\title{
PREVALENCE OF MATERNAL NEAR-MISS AND MATERNAL MORTALITY, THEIR DISTRIBUTION BY GESTATION AND GRAVIDITY AND CAUSES IN WOMEN WITH LIVE BIRTHS IN DISTRICT PESHAWAR, PAKISTAN
}

\author{
Sonia Rafiq1, Sumaira Yasmin', iD Nazia Liaqat', Ghazala Shams² \\ Departments of Obstetrics \& Gynaecology, ${ }^{1}$ Lady Reading Hospital \& ${ }^{2}$ Khyber Girls Medical College, \\ Peshawar, Pakistan
}

\begin{abstract}
Background: Maternal near-miss (MNM) and maternal mortality (MM) are indicators for quality of health care system. The objectives of our study were to determine prevalence of MNM and MM and their distribution by gestation and gravidity and their causes in women with live births population of District Peshawar, Pakistan.

Material \& Methods: This cross-sectional study was conducted at Department of Obstetrics and Gynaecology, Lady Reading Hospital, Peshawar, Pakistan from January 2017 to June 2017. From assumed population of 185,676 pregnant women in District Peshawar, 10\% prevalence of MNM, 1.0448\% margin of error and 95\%CL, sample size was calculated 3,115. All women with live birth were eligible. Presence of MNM and MM, causes of MNM and $\mathrm{MM}$, gestational age and gravidity were six variables. Being nominal, all were analysed by count and ratio or percentage with $80 \% \mathrm{Cl}$. MNM Ratio was calculated per 1,000 live births and MM Ratio per 100,000 live births.

Results: Out of 3,115 women with live births, MNM cases were 494 with MNMR 158.59/1,000 (80\%Cl 150.19166.97) and MM cases were 16 with MMR 513.64/100,000 population (95\% Cl 349.50-677.78). There were 232 MNM cases in $\leq 28$ weeks and 262 in $>28$ weeks gestational age with similar MNMR between these groups. There were 244 MNM cases in primigravida and 250 in multigravida with similar MNMR between these groups. There were five MM cases in $\leq 28$ weeks and 11 in $>28$ weeks gestational age with similar MMR between these groups. There were five MM cases in primigravida and 11 in multigravida with similar MMR between these groups as their Cls are overlapping. Haemorrhage was most common cause for MNM in $365(11.7175 \%)$ cases and for $\mathrm{MM}$ in $8(0.2568 \%)$ cases.

Conclusion: The maternal near-miss ratio (MNMR) and maternal mortality ratio (MMR) are relatively higher in population of District, Peshawar, Pakistan. MNMR and MMR both have similar prevalence in $\leq 28$ weeks and in $>28$ weeks gestational age groups and also similar in primigravida and in multigravida groups. Haemorrhage (antepartum and postpartum) was most common cause both for maternal near-miss (MNM) and maternal mortality (MM).
\end{abstract}

KEY WORDS: Maternal Near-miss; Maternal Mortality; Maternal Deaths; Eclampsia; Haemorrhage; Sepsis.

Cite as: U Rafiq S, Yasmin S, Liaqat N, Shams G. Prevalence of maternal near-miss and maternal mortality, their distribution by gestation and gravidity and causes in women with live births in District Peshawar, Pakistan. Gomal J Med Sci 2021 Apr-Jun; 19(2):58-65. https://doi.org/10.46903/gjms/19.02.844

\section{Corresponding Author:}

Dr. Sumaira Yasmin

Assistant Professor

Department of Obstetrics and Gynaecology

Lady Reading Hospital, Peshawar, Pakistan

E-mail: drsumairayasmin@gmail.com

Date Submitted:

Date Revised:

Date Accepted:
16-02-2021

23-03-2021

30-03-2021

\section{INTRODUCTION}

1.1 Background: As per WHO statement, amidst the objectives for health determinants for the millennium, the maternal mortality rate (MMR) is an indicator of paramount importance in maternal health. ${ }^{1}$ Globally maternal death ratio for 2017 was estimated at 211 deaths per 100,000 live births. ${ }^{2}$ Reduction in maternal mortality ratio indicates improvement in health care system. 
There are patients who are termed near-miss patients who in spite of development of deadly obstetric complications during pregnancy and postpartum period of up to 42 days, survived that complication. ${ }^{3}$ Thus patients presenting with severe obstetric complications are of paramount importance as they may end up as near-miss or even in maternal mortality. These obstetric determinants need to be highlighted and prevented in order to achieve the goals of improved maternal health

In 2010, WHO and UNICEF adjusted the various maternal mortality statistics and proclaimed the death of almost 358,000 women around the world from maternal causes, including $87 \%$ in Africa and Asia. ${ }^{4}$ In 2015 in Pakistan, MMR was 276/100,000 live births. ${ }^{5}$ In order to improve provision of healthcare system to the people, near-miss events and the nearmiss statistics must be included in national health indicators. According to $2009 \mathrm{WHO}$ consensus, timely and ample treatment for obstetric complications can be given on maternal near-miss definition and set criteria for case identification by defining the criteria. ${ }^{6,7}$
For Pakistan, the great challenging Millennium Development Goal (MDG) is to decrease maternal mortality. An inclusive access is required as it is interconnected with several more social factors. An influential tool for policy makers could be important for analyzing and evaluating near-miss with health care system.

1.2 Research Objectives (RO): To determine the;

RO 1-2: prevalence of maternal near-miss and maternal mortality in women with live births population of District Peshawar, Pakistan.

RO 3-6: distribution of maternal near-miss and maternal mortality by gestational age and gravidity in women with live births population of District Peshawar, Pakistan.

RO 7-8: causes of maternal near-miss and maternal mortality in women with live births population of District Peshawar, Pakistan.

\subsection{Operational Definitions}

Table 1.3 shows operational definitions used in this study.

Table 1.3: Operational definitions in a study for prevalence of maternal near-miss and maternal mortality

\begin{tabular}{|c|c|}
\hline $\begin{array}{l}\text { Maternal death } \\
\text { (Mortality) (MM) }\end{array}$ & $\begin{array}{l}\text { "Maternal death is defined as death of a woman while pregnant or within } 42 \text { days of ter- } \\
\text { mination of pregnancy, irrespective of the duration and the site of the pregnancy, from } \\
\text { any cause related to or aggravated by the pregnancy or its management, but not from } \\
\text { accidental or incidental causes". }\end{array}$ \\
\hline $\begin{array}{l}\text { Maternal near-miss } \\
\text { (MNM) }\end{array}$ & $\begin{array}{l}\text { "A MNM case is defined as a woman who nearly died but survived a complication that } \\
\text { occurred during pregnancy, childbirth or within } 42 \text { days of termination of pregnancy". }{ }^{, 9}\end{array}$ \\
\hline $\begin{array}{l}\text { Severe maternal } \\
\text { outcomes }\end{array}$ & $\begin{array}{l}\text { "SMO refers to a life-threatening condition (i.e. organ dysfunction), including all maternal } \\
\text { deaths and maternal near-miss cases". }{ }^{10}\end{array}$ \\
\hline Live birth & "LB refers to the birth of an offspring which breathes or shows evidence of life". ${ }^{10}$ \\
\hline MNM ratio (MNMR) & $\begin{array}{l}\text { "MNMR refers to the number of maternal near-miss cases per } 1000 \text { live births (MN- } \\
\text { MR=MNM/LB)". }{ }^{10}\end{array}$ \\
\hline $\begin{array}{l}\text { Severe postpartum } \\
\text { haemorrhage }\end{array}$ & $\begin{array}{l}\text { "Genital bleeding after delivery, with at least one of the following: perceived abnormal } \\
\text { bleeding ( } 1000 \mathrm{ml} \text { or more) or any bleeding with hypotension or blood transfusion". }{ }^{10}\end{array}$ \\
\hline $\begin{array}{l}\text { Severe } \\
\text { pre-eclampsia }\end{array}$ & $\begin{array}{l}\text { "Persistent systolic blood pressure of } 160 \mathrm{mmHg} \text { or more or a diastolic blood pressure of } \\
110 \mathrm{mmHg} \text {; proteinuria of } 5 \mathrm{~g} \text { or more in } 24 \text { hours; oliguria of }<400 \mathrm{ml} \text { in } 24 \text { hours; and } \\
\text { HELLP syndrome or pulmonary oedema. Excludes Eclampsia". }{ }^{10}\end{array}$ \\
\hline Eclampsia & $\begin{array}{l}\text { "Generalized fits in a patient without previous history of epilepsy. Includes coma in } \\
\text { pre-eclampsia". }{ }^{10}\end{array}$ \\
\hline $\begin{array}{l}\text { Severe systemic } \\
\text { infection or sepsis }\end{array}$ & $\begin{array}{l}\text { "Presence of fever (body temperature }>38^{\circ} \mathrm{C} \text { ), a confirmed or suspected infection (e.g. } \\
\text { chorioamnionitis, septic abortion, endometritis, pneumonia), and at least one of the } \\
\text { following: heart rate }>90 \text {, respiratory rate }>20 \text {, leukopenia (white blood cells }<4000 \text { ), } \\
\text { leukocytosis (white blood cells }>12000 \text { )". }{ }^{10}\end{array}$ \\
\hline Uterine rupture & "Rupture of uterus during labour confirmed by laparotomy". ${ }^{10}$ \\
\hline
\end{tabular}




\section{MATERIALS AND METHODS}

2.1 Design, Setting \& Duration: This cross-sectional study was conducted at the Department of Obstetrics and Gynaecology, Lady Reading Hospital, Peshawar, Pakistan from January 2017 to June 2017. The Ethical Review Board of the institution accorded approval to the study. Formal consent of patients/ attendants was sought for inclusion in the study.

2.2 Population \& Sampling: The population of District Peshawar was assumed to be 4.2 million in first half of 2017. It included 2,032,800 $(48.4 * 4,200,000 / 100=2,032,800)$ women, which further included $928,380(45.67 * 2,032,800 / 100=92$ $8,379.76)$ women in child bearing age (15-49 years). Assuming $20 \%$ pregnancy in this age group, we will have 185,676 $(928,380 * 20 / 100)$ pregnant women; our population at risk for maternal near-miss and maternal mortality. With this much population, assumed prevalence of maternal near-miss as $10 \%$ in this population, $1.0448 \%$ margin of error and $95 \% \mathrm{CL}$, sample size $^{11}$ came to be 3,115 , using consecutive method. All women with live birth were eligible for inclusion.

2.3 Conduct of Procedure: All these pregnant women were admitted for deliveries. History was taken and general physical and obstetrical examinations were done. Routine investigations, including urine $\mathrm{R} / \mathrm{E}$, blood complete with ESR, $\mathrm{ABO} / \mathrm{Rh}$ grouping and pelvic USG were conducted. Routine management for delivery was offered. In case of complications, standard protocols were employed, including relevant investigations and relevant treatment, including but not limited to IV line, IV fluids and blood transfusion etc.

2.4 Data Collection Plan: Presence of maternal near-miss (yes \& no), presence of maternal mortality (yes \& no), causes of MNM and causes of MM were four research variables (attributes), while gestational age ( $\leq 28$ weeks $\&>28$ weeks) and gravidity (primigravida \& multigravida) were two grouping variables/ factors (attributes). The measurement scale for all these variables was nominal.

2.5 Data Analysis Plan: The data for the sample was analysed by count and ratio (MNMR \& MMR), while it was inferred on to the population as confidence interval for MNMR \& MMR at $80 \%$ confidence level, using Wilson score interval method. ${ }^{12}$

For causes of MNM and MM, counts and percentages were calculated with $\mathrm{Cl}$ at $80 \% \mathrm{CL}$, using Wilson score interval method. ${ }^{12}$ The comparison of prevalence among the sub-samples was based upon their confidence intervals (Cls) i.e. estimated parameters for proportion for population, not their counts for the sub-samples. The prevalence was considered as similar when there was overlapping of Cls, otherwise dissimilar. MMR was evaluated per 100,000 live births, whereas MNMR was evaluated using 1,000 live births as the denominator.

\section{RESULTS}

3.1 Prevalence of MNM and MM: Out of 3,115 women with live births, there were 494 MNM cases with maternal near-miss ratio (MNMR) of $158.59 / 1,000$ $(494 * 1,000 / 3,115=158.59)$ population $(95 \% \mathrm{Cl}$ 150.19-166.97).

There were $16 \mathrm{MM}$ cases with maternal mortality ratio (MMR) of 513.64/100,000 $(16 * 100,000 / 3,115=513.64)$ population (95\% Cl 349.50-677.78).

3.2 Distribution of MNM by gestational age and gravidity: There were 232 MNM cases with MNMR of $74.48 / 1,000(80 \% \mathrm{Cl} 68.67-80.73)$ in $\leq 28$ weeks and 262 MNM cases with MNMR of $84.11 / 1,000$ $(80 \% \mathrm{Cl} 77.95-90.70)$ in $>28$ weeks gestational age. The MNMR was similar between these groups, as their Cls are overlapping. (Table 3.2)

There were 244 MNM cases with MNMR of $78.33 / 1,000$ $(80 \% \mathrm{Cl} 72.38-84.72)$ in primigravida and $250 \mathrm{MNM}$ cases with MNMR of 80.26/1,000 (Cl 74.23-86.71) in multigravida. The MNMR was similar between the primigravida and multigravida groups as their Cls are overlapping. (Table 3.2)

Table 3.2: Distribution of maternal near-miss (MNM) by gestational age and gravidity in women with live births population of District Peshawar $(n=3,115)$

\begin{tabular}{|l|l|c|c|c|c|}
\hline \multirow{2}{*}{ Variable } & \multirow{2}{*}{ Attributes } & \multicolumn{2}{|c|}{ Sample analysis for MNM } & \multicolumn{2}{c|}{$\begin{array}{c}\text { Estimated MNM Ratio/1,000 live } \\
\text { births in population at } 80 \% \mathrm{CL}\end{array}$} \\
\cline { 3 - 6 } & Count & $\begin{array}{c}\text { MNM Ratio/1,000 live } \\
\text { births }\end{array}$ & Lower & Upper \\
\hline \multirow{2}{*}{ Gestational age } & $\leq 28$ weeks & 232 & $232^{*} 1,000 / 3,115=74.48$ & 68.67 & 80.73 \\
\cline { 2 - 6 } & $>28$ weeks & 262 & $262^{*} 1,000 / 3,115=84.11$ & 77.95 & 90.70 \\
\hline \multirow{2}{*}{ Gravidity } & Primigravida & 244 & $244^{*} 1,000 / 3,115=78.33$ & 72.38 & 84.72 \\
\cline { 2 - 6 } & Multigravida & 250 & $250^{*} 1,000 / 3,115=80.26$ & 74.23 & 86.71 \\
\hline \multicolumn{2}{|l|}{ Cases with MNM } & 494 & $494^{*} 1,000 / 3,115=158.59$ & 150.38 & 167.15 \\
\hline \multicolumn{2}{|l|}{ Cases with no MNM } & 2,621 & $2,621^{*} 1,000 / 3,115=841.41$ & 823.84 & 849.62 \\
\hline \multicolumn{2}{|l}{ Total } & 3,115 & 3,115 & \multicolumn{2}{|c|}{ Population parameters } \\
\hline
\end{tabular}


3.3 Distribution of maternal mortality (MM) by gestational age and gravidity: There were $05 \mathrm{MM}$ cases with MMR of $160.51 / 100,000(80 \% \mathrm{Cl} 192.20$ 282.35 ) in $\leq 28$ weeks and $11 \mathrm{MM}$ cases with MMR of $353.13 / 100,000(80 \% \mathrm{Cl} 240.62-517.95)$ in $>28$ weeks gestational age. The MMR was similar between these groups, as their Cls are overlapping. (Table 3.3)

There were $05 \mathrm{MM}$ cases with MMR of $160.51 / 100,000$ $(80 \% \mathrm{Cl} 192.20-282.35)$ in primigravida and $11 \mathrm{MM}$ cases with MMR of $353.13 / 100,000(80 \% \mathrm{Cl} 240.62$ $517.95)$ in multigravida. The MMR was similar be- tween the primigravida and multigravida groups as their Cls are overlapping. (Table 3.3)

3.4 Causes of MNM: Haemorrhage (including antepartum and postpartum) was the most common cause for MNM in 365 (11.7175\%) cases, while sepsis was the least common cause in four $(0.1284)$ cases. (Table 3.4)

3.5 Causes of MM: Haemorrhage (including antepartum and postpartum) was the most common cause for MM in $8(0.2568 \%)$ cases, while all other causes were in two $(0.0642 \%)$ cases each. (Table 3.5$)$

Table 3.3: Distribution of MM by gestational age and gravidity in women with live births population of District Peshawar $(n=3,115)$

\begin{tabular}{|c|c|c|c|c|c|}
\hline \multirow[t]{2}{*}{ Variable } & \multirow[t]{2}{*}{ Attributes } & \multicolumn{2}{|c|}{ Sample analysis for MM } & \multicolumn{2}{|c|}{$\begin{array}{l}\text { Estimated MM Ratio/ } 100,000 \text { live } \\
\text { births in population at } 80 \% \mathrm{CL}\end{array}$} \\
\hline & & Count & MM Ratio/100,000 live births & Lower & Upper \\
\hline \multirow{2}{*}{$\begin{array}{l}\text { Gestational } \\
\text { age }\end{array}$} & $\leq 28$ weeks & 05 & $05 * 100,000 / 3,115=160.51$ & 91.20 & 282.35 \\
\hline & $>28$ weeks & 11 & $11 * 100,000 / 3,115=353.13$ & 240.62 & 517.95 \\
\hline \multirow[b]{2}{*}{ Gravidity } & Primigravida & 05 & $05 * 100,000 / 3,115=160.51$ & 91.20 & 282.35 \\
\hline & Multigravida & 11 & $11 * 100,000 / 3,115=353.13$ & 240.62 & 517.95 \\
\hline \multicolumn{2}{|c|}{ Cases with MM } & 16 & $16 * 100,000 / 3,115=513.64$ & 373.56 & 705.87 \\
\hline \multicolumn{2}{|c|}{ Cases with no MM } & 3,099 & $3,099 * 100,000 / 3,115=99486.36$ & 99294.12 & 99626.44 \\
\hline \multicolumn{2}{|l|}{ Total } & 3,115 & 3,115 & \multicolumn{2}{|c|}{ Population parameters } \\
\hline
\end{tabular}

Table 3.4: Causes of MNM in women with live births population of District Peshawar $(n=3,115)$

\begin{tabular}{|l|l|l|l|l|}
\hline \multirow{2}{*}{ Attributes } & \multicolumn{2}{|l|}{ Sample statistics for causes for MNM } & $80 \% \mathrm{Cl}$ for proportion \\
\cline { 2 - 5 } & Count & Percentage & Lower & Upper \\
\hline Haemorrhage (APH/PPH) & 365 & $365^{\star} 100 / 3,115=11.7175$ & 10.9991 & 12.4763 \\
\hline $\begin{array}{l}\text { Hypertensive disorders (Eclampsia, } \\
\text { Pre-eclampsia, HELLP syndrome) }\end{array}$ & 120 & $120^{\star} 100 / 3,115=03.8523$ & 3.4341 & 4.3191 \\
\hline Sepsis & 04 & $04^{\star} 100 / 3,115=0.1284$ & 0.0683 & 0.2409 \\
\hline Indirect causes & 05 & $05^{\star} 100 / 3,115=0.1605$ & 0.0912 & 0.2823 \\
\hline Cases with MNM & 494 & $494^{\star} 100 / 3,115=15.8587$ & 15.0380 & 16.7155 \\
\hline Cases with no MNM & 2,621 & $2,621^{\star} 100 / 3,115=84.1413$ & 83.2845 & 84.9620 \\
\hline Total & 3,115 & $3,115(100 \%)$ & Population parameters \\
\hline
\end{tabular}

Table 3.5: Causes of MM in women with live births population of District Peshawar $(n=3,115)$

\begin{tabular}{|l|l|l|l|l|}
\hline \multirow{2}{*}{ Attributes } & \multicolumn{2}{|l|}{ Sample statistics for causes for MM } & $80 \% \mathrm{Cl}$ for proportion \\
\cline { 2 - 5 } & Count & Percentage & Lower & Upper \\
\hline Haemorrhage (APH/PPH) & 08 & $08^{\star} 100 / 3,115=0.2568$ & 0.1639 & 0.4021 \\
\hline $\begin{array}{l}\text { Hypertensive disorders (Eclampsia, } \\
\text { Pre-eclampsia, HELLP syndrome) }\end{array}$ & 02 & $02^{\star} 100 / 3,115=0.0642$ & 0.0266 & 0.1543 \\
\hline Sepsis & 02 & $02 * 100 / 3,115=0.0642$ & 0.0266 & 0.1543 \\
\hline Indirect causes & 02 & $02^{\star} 100 / 3,115=0.0642$ & 0.0266 & 0.1543 \\
\hline Anaesthesia complications & 02 & $02^{\star} 100 / 3,115=0.0642$ & 0.0266 & 0.1543 \\
\hline Cases with MM & 16 & $16 * 100 / 3,115=0.5136$ & 0.3735 & 0.7058 \\
\hline Cases with no MM & 3,099 & $3,099^{\star} 100 / 3,115=99.4864$ & 99.2941 & 99.6264 \\
\hline Total & 3,115 & $3,115(100 \%)$ & Population parameters \\
\hline
\end{tabular}




\section{DISCUSSION}

4.1 Prevalence of MNM/ MNM Ratio and MM/ MM Ratio: In our study, out of 3,115 women with live births, there were 494 maternal near-miss (MNM) cases with maternal near-miss ratio (MNMR) of $158.59 / 1,000$ population $(95 \% \mathrm{Cl} 150.19-166.97)$.

There were 16 maternal mortality (MM) cases with maternal mortality ratio (MMR) of $513.64 / 100,000$ population $(95 \% \mathrm{Cl} 349.50-677.78)$.

Table 4.1 shows MNM cases \& MNM Ratio from 17 studies and MM cases \& MM Ratio from 18 different studies/ populations. Comparisons for MNMR and MMR are based on their confidence intervals of ratios for population, not on their ratios for the sample.

Here MNM Ratios of all these 17 populations/ studies are lower than our study.

MM Ratio is reported similar to our study by Ansari, et al. ${ }^{14}$ It is reported higher than our study by Mustafa, et al. ${ }^{17}$, Sultana, et al. ${ }^{18}$, Amita, et al ${ }^{21}$, Alemu, et al ${ }^{24}$,
Oladapo, et al. ${ }^{26}$, and Akpan, et al. ${ }^{27}$

MM Ratio is reported lower than our study by Shaheen, et al. ${ }^{13}$, Shahid, et al. ${ }^{15}$, Aziz, et al. ${ }^{16}$, Roopa, et al. ${ }^{19}$, Singh, et al. ${ }^{20}$, Kansara, et al. ${ }^{22}$, Dhingra, et al. ${ }^{23}$, Heemelaar, et al. ${ }^{25}$, Chikadaya, et al. ${ }^{28}$, David, et al. ${ }^{29}$ and Lotufo, et al..$^{30}$

The caliber of maternal health care is illustrated by obstetric death. In our part of the world the near-misses are not usually used as a measure of the obstetric quality care as is also not used in many regions having increased MMR.

In our project, we have sorted out the maternal nearmiss cases. In our study/ population, the MNMR was $158.59 / 1,000$ live birth, which is quite high. It could be due to the fact that we used the morbidity and organ system based criteria for the diagnosis of MNM patients. We have not used intensive care admission criteria for near-miss. Due to overburdened ICU in our setup, most of the mothers with severe morbidity are dealt with in our obstetric units in close liaison

Table 4.1: MNM \& MNM Ratio and MM \& MM Ratio for different populations

\begin{tabular}{|c|c|c|c|c|c|c|c|c|c|}
\hline $\begin{array}{l}\text { S. } \\
\text { No. }\end{array}$ & Author & City & Country & Duration & $\begin{array}{l}\text { Live } \\
\text { births }\end{array}$ & $\begin{array}{l}\text { MNM } \\
\text { cases }\end{array}$ & $\begin{array}{l}\text { MNM Ra- } \\
\text { tio/1000 }\end{array}$ & $\begin{array}{c}\text { MM } \\
\text { cases }\end{array}$ & $\begin{array}{c}\text { MM Ratio/ } \\
100,000\end{array}$ \\
\hline & Our study & Peshawar & Pakistan & 2017 & 3115 & 494 & 158.59 & 16 & 513.64 \\
\hline 1 & Shaheen, et al. ${ }^{13}$ & Rawalpindi & Pakistan & 2012-13 & 15757 & 198 & 12.56 & 49 & 310.97 \\
\hline 2 & Ansari, et al. ${ }^{14}$ & Kharian & Pakistan & 2013 & 1035 & 76 & 73.43 & 7 & 676.32 \\
\hline 3 & Shahid, et al. ${ }^{15}$ & Lahore & Pakistan & 2014 & 2371 & 124 & 52.29 & 7 & 295.23 \\
\hline 4 & Aziz, et al. ${ }^{16}$ & $\begin{array}{l}\text { District } \\
\text { Thatta }\end{array}$ & Pakistan & $2010-18$ & 87172 & & & 278 & 318.90 \\
\hline 5 & Mustafa, et al. ${ }^{17}$ & Karachi & Pakistan & 2006 & 822 & 44 & 53.52 & 6 & 729.92 \\
\hline 6 & Sultana, et al. ${ }^{18}$ & Karachi & Pakistan & 2018 & 1811 & 57 & 31.47 & 15 & 828.27 \\
\hline 7 & Roopa, et al. ${ }^{19}$ & Manipal & India & 2011-12 & 7330 & 131 & 17.87 & 23 & 313.77 \\
\hline 8 & Singh, et al..$^{20}$ & $\begin{array}{l}\text { Jamshed- } \\
\text { pur }\end{array}$ & India & 2016-19 & 14636 & 153 & 10.45 & 38 & 259.63 \\
\hline 9 & Amita, et al. ${ }^{21}$ & Lucknow & India & 2011-12 & 5273 & 633 & 120.04 & 247 & 4684.24 \\
\hline 10 & Kansara, et al. ${ }^{22}$ & $\begin{array}{l}\text { Ahmed- } \\
\text { abad }\end{array}$ & India & 2019 & 3200 & 16 & 5 & 6 & 187.50 \\
\hline 11 & Dhingra, et al. ${ }^{23}$ & Delhi & India & 2012-14 & 18631 & 161 & 8.64 & 35 & 187.85 \\
\hline 12 & Alemu, et al. ${ }^{24}$ & Juba & $\begin{array}{l}\text { South } \\
\text { Sudan }\end{array}$ & 2016 & 994 & 94 & 94.57 & 10 & 1006.03 \\
\hline 13 & Heemelaar, et al. ${ }^{25}$ & Windhoek & Namibia & 2018 & 5772 & 194 & 33.61 & 9 & 155.92 \\
\hline 14 & Oladapo, et al. ${ }^{26}$ & Nationwide & Nigeria & $2012-13$ & 91724 & 1451 & 15.81 & 998 & 1088.04 \\
\hline 15 & Akpan, et al. ${ }^{27}$ & Calabar & Nigeria & $2012-16$ & 10111 & 691 & 68.34 & 99 & 979.13 \\
\hline 16 & Chikadaya, et al. ${ }^{28}$ & Harare & Zimbabwe & 2016 & 11871 & 110 & 9.26 & 13 & 109.51 \\
\hline 17 & David, et al. ${ }^{29}$ & Maputo & $\begin{array}{l}\text { Mozam- } \\
\text { bique }\end{array}$ & 2008 & 27916 & 564 & 20.20 & 71 & 254.33 \\
\hline 18 & Lotufo, et al. ${ }^{30}$ & Limeria & Brazil & 2004-07 & 9683 & 43 & 4.44 & 5 & 51.63 \\
\hline
\end{tabular}


with ICU staff. They are not fortunate enough to get admission in ICU, yet quite fortunate to escape mortality. This has led to a higher enrollment of women in near-miss cases.

In our setup MMR was 513.64/100,000 live births which is quiet high. The reasons could be that we usually receive critically serious patients coming from far off areas who have delays in referrals from primary care facilities as well as in their transportation. Moreover, most of these patients are attended by untrained traditional birth attendants, who are unaware of the warning signs and they try to handle the patient till the very end. As a result, the patients with postpartum hemorrhage and ruptured uterus are usually received in irreversible shocks. These patients lose their golden hour of resuscitation either at their primary place or on the way to hospital.

4.2 Distribution of MNM by gestational age and gravidity: Our study showed 494 MNM cases, including 232 cases in $\leq 28$ weeks and 262 in $>28$ weeks gestational age. The MNMR was similar between these groups, as their Cls are overlapping. (Table 3.2) Opposing to our study, Singh, et al..$^{20}$ reported 153 MNM cases out of 14,636 live births. Here MNM was more common in $>28$ weeks gestational age as 115 $(75.1 \%)$ than $\leq 28$ weeks as $38(24.9 \%)$ cases. Most of the complications are observed in late pregnancy after 28 weeks of gestation. Consequently MNM and MM are more frequently seen in gestational age of more than 28 weeks as compared with lesser gestational ages. More vigilant monitoring of patients with any obstetric complications in late trimester of pregnancy is thus needed.

Our study showed 244 MNM cases in primigravida and 250 in multigravida. The MNMR was similar between the primigravida and multigravida groups as their Cls are overlapping. (Table 3.2)

Opposing to our study, Singh, et al. ${ }^{20}$ reported 153 MNM cases out of 14,636 live births. Here MNM was more common in multigravida $96(62.7 \%)$ than primigravida 57 (37.3\%).

4.3 Distribution of MM by gestational age and gravidity: Our study showed $494 \mathrm{MM}$ cases, including 05 cases in $\leq 28$ weeks and 11 in $>28$ weeks gestational age. The MMR was similar between these groups, as their Cls are overlapping. (Table 3.3)

Opposing to our study, Singh, et al. ${ }^{20}$ reported $38 \mathrm{MM}$ cases out of 14,636 live births. Here MM was more common in $>28$ weeks gestational age as 36 (94.7\%) than $\leq 28$ weeks as two (5.3\%) cases.

Our study showed $05 \mathrm{MM}$ cases in primigravida and 11 in multigravida. The MMR was similar between the primigravida and multigravida groups as their Cls are overlapping. (Table 3.3)

Opposing to our study, Singh, et al. ${ }^{20}$ reported $38 \mathrm{MM}$ cases out of 14,636 live births. Here MM was more common in multigravida $28(73.7 \%)$ than primigravida 10 (26.3\%).

Our study showed maternal near-miss to maternal mortality ratio of $1: 31$, which means for every 31 life threatening obstetric complications who survived, there was one maternal death. Better health care is revealed by large ratios. Many studies have showed lower maternal mortality to near-miss ratio of $1: 4$ by Shaheen, et al. ${ }^{13}$, from Rawalpindi, Pakistan, 1:10.85 by Ansari, et al. ${ }^{14}$ from Kharian, Pakistan, $1: 7$ by Mustafa, et al. ${ }^{17}$ from Karachi, Pakistan, 1:4 by Singh, et al. ${ }^{20}$ from Jamshedpur, India, $1: 2.56$ by Pandey, et al. ${ }^{21}$ from Lucknow, India, and $1: 8.5$ by Chikadaya, et al. ${ }^{28}$ form Harare, Zimbabwe. This ratio is indicative of the standard of obstetrical care. In case this ratio rises over a period of time, it reflects the advancement attained in obstetric health care. So instead of a single estimation, yearly estimation may help us in improving the care provided.

4.4 Causes of MNM and MM: Our study showed haemorrhage (including antepartum and postpartum) as the most common cause for MNM in 365 (11.7175\%) cases, while sepsis was the least common cause in four (0.1284) cases. (Table 3.4)

Our study showed haemorrhage (including antepartum and postpartum) as the most common cause for $\mathrm{MM}$ in $08(0.2568 \%)$ cases, while all other causes were in two $(0.0642 \%)$ cases each. (Table 3.5$)$

Among the causes of near-miss events, hemorrhage $(31.8 \%)$ was the leading cause, followed by hypertensive disorders (28.2\%) as depicted by Chikadaya, et al. ${ }^{28}$ from Harare, Zimbabwe.

Ours Lady Reading Hospital is a teaching hospital, providing services to population of district Peshawar and surrounding areas. Here most cases are received in already serious condition; therefore mortality index for sepsis and indirect causes is high. The delays in referrals and in transportation are considered as major causes for increased morbidity and mortality.

Haemorrhage, hypertensive disorders and puerperal sepsis were the leading causes of near-miss cases. Maternal near-miss have its own implications on mother as well as the new born baby, including many psycho-social effects in addition to the physical distress to the mother. MNM is increasingly used as an indicator for quality of obstetric care and clinical practice.

As near-miss analysis indicates quality of health care, it is important to be notified in the national health care indices in order to reduce the high maternal mortality. The high risk groups of patients are to be identified and special care to be given to these targeted populations. Similarly, more high risk groups are to be identified in a large scale studies as the limitation of the study is that it is a single center audit data, setting collection spanning over six months period. 
4.5 Marwat Logical Trajectory of Research Process: We have employed this 8-steps hierarchical research model in our project, developed by Dr. Muhammad Marwat. ${ }^{31-33}$

\section{CONCLUSION}

The maternal near-miss ratio (MNMR) and maternal mortality ratio (MMR) are relatively higher in population of District, Peshawar, Pakistan. MNMR and MMR both have similar prevalence in $\leq 28$ weeks and in $>28$ weeks gestational age groups and also similar in primigravida and in multigravida groups. Haemorrhage (antepartum and postpartum) was most common cause both for maternal near-miss (MNM) and maternal mortality (MM).

\section{REFERENCES}

1. Say L, Pattinson RC, Gülmezoglu AM. WHO systematic review of maternal morbidity and mortality: The prevalence of severe acute maternal morbidity (near miss). Reprod Health 2004; 1 : 3. https://doi.org/10.1186/1742-4755-1-3

2. Estimates by WHO, UNICEF, UNFPA, World Bank Group and the United Nations Population Division, Published September 2019; ISBN: 978-92.

3. Tunçalp O, Hindin MJ, Souza JP, Chou D, Say L. The prevalence of maternal near miss: A systematic review. BJOG 2012;119:653-61. https://doi. org/10.1111/j.1471-0528.2012.03294.x

4. Unicef. Pakistan Annual Report 2013. Islamabad, Pakistan: UNICEF Pakistan 2014. Available at: https://issuu.com/headbumped/docs/unicef_annual_report_2013

5. Demographic and Health Survey Pakistan 20172018. MEASUREDHS: Demographic and Health Surveys. National Institute of Population Studies (NIPS). Available at: http://nips.org.pk/abstract files/PDHS\%20-\%202017-18\%20Key\%20 indicator\%20Report\%20Aug\%202018.pdf

6. Say L, Souza JP, Pattinson RC. Maternal near miss-towards a standard tool for monitoring quality of maternal health care. Best Pract Res Clin Obstet Gynaecol 2009;23(3):287-96. https://doi. org/10.1016/j.bpobgyn.2009.01.007

7. Kumar M, Naik G. Maternal near miss: reaching the last mile. J Obstet Gynaecol 2020 Dec;2:1-9.

8. International Statistical Classification of Diseases and related health problems. 10th revision, Volume 2. Geneva. World Health Organization 1993.

9. Report on the World Health Organization Working Group on the classification of maternal deaths and severe maternal morbidities. Geneva. World Health Organization 2009.

10. WHO. Evaluating the quality of care for severe pregnancy complications. The WHO near-miss approach for maternal health. Geneva. World Health Organization 2011.

11. Raosoft $\circledast$ sample size calculator [internet]. Seattle, WA, USA: Raosoft Inc.; 2004. [accessed
2021 Feb 13]. Available at: http://www. raosoft. com/samplesize.html

12. Statistics Kingdom. Proportion confidence interval calculator [internet]. Statistics Kingdom; Melbourne, Australia 2007. [accessed 2021 Feb 13]. Available at: http://www.statskingdom. com/41_proportion_confidence_interval.html

13. Shaheen F. Maternal near miss. J Rawalpindi Med Coll 2014 Jun 30; 18(1):130-2.

14. Ansari A, Zubair U, Parveen S, Tasleem G. Near miss obstetric events \& maternal health. Pak Armed Forces Med J 2016;66(1):98-103.

15. Shahid A, Rizwan S, Khawaja N. Near miss events frequency and most common causes. Pak J Med Health Sci 2015 Jul-Sep;9(3):920-2.

16. Aziz A, Saleem S, Nolen TL, Pradhan NA, McClore EM, Jessani S, et al. Why are the Pakistani maternal, fetal and newborn outcomes so poor compared to other low and middle-income countries? Reprod Health 2020; 17(Suppl 3):190. https://doi. org/10.1186/s12978-020-01023-5

17. Mustafa R and Hashmi H. Near-miss obstetrical events and maternal death. J Coll Physicians Surg 2009;19(12):781-5.

18. Sultana $S$, Ishtiaque $S$, Fareed $S$, et al. Clinical spectrum of near-miss cases in obstetrics. Cureus 2019;11(5):e4641. https://doi.org/10.7759/ cureus. 4641

19. Roopa PS, Verma S, Rai L, Kumar P, Pai MV, Shetty J. Near miss obstetric events and maternal deaths in a tertiary care hospital: an audit. J Pregnancy 2013;2013:393758. https://doi. org/10.1155/2013/393758

20. Singh V, Barik A. Maternal near-miss as a surrogate indicator of the quality of obstetric care: a study in a tertiary care hospital in Eastern India. Cureus 2021 Jan;13(1): e12548. https://doi. org/10.7759/cureus.12548

21. Pandey A, Das V, Agarwal A, Agrawal S, Misra $D$, Jaiswal N. Evaluation of obstetric near miss and maternal deaths in a tertiary care hospital in north India: shifting focus from mortality to morbidity. J Obstet Gynaecol India 2014 Dec; 64(6):394-9. https://doi.org/10.1007/s13224014-0552-1

22. Kansara V, Vaja D, Desai A. Incidence of maternal near-miss events in a tertiary care hospital of Gujarat, India. Int J Reprod Contracept Obstet Gynecol 2020 Jan;9(1):145-50. https://doi. org/10.18203/2320-1770.ijrcog20196011

23. Dhingra S, Yadav R, Raghudandan C. A study of near miss obstetric events and maternal deaths in a tertiary care hospital. Int J Adv Res 2017 Jan;5(1):2172-8. https://doi.org/10.21474/ IJAR01/2992

24. Alemu FM, Fuchs MC, Martin Vitale T, Abdalla Mohamed Salih M. Severe maternal morbidity (near-miss) and its correlates in the world's newest nation: South Sudan. Int J Womens Health 2019 Mar 19;11:177-90. https://doi.org/10.2147/ IJWH.S160022 
25. Heemelaar S, Kabongo L, Ithindi T, Luboya C, Munetsi F, Bauer AK, et al. Measuring maternal near-miss in a middle-income country: assessing the use of $\mathrm{WHO}$ and sub-Saharan Africa maternal near-miss criteria in Namibia. Global health action. 2019 Jan 1;12(1):1646036. https://doi.org/ 10.1080/16549716.2019.1646036

26. Oladapo OT, Adetoro OO, Ekele BA, Chama C, Etuk SJ, Aboyeji AP, et al.When getting there is not enough: a nationwide cross-sectional study of 998 maternal deaths and 1451 near-misses in public tertiary hospitals in a low-income country. BJOG 2016 May;123(6):928-38. https://doi. org/10.1097/01.aoa.0000512012.96214.08

27. Apkan UB, Asibong U, Omoronyia E, Arogundade K, Agan T, Ekott M. Severe life-threatening pregnancy complications, "near miss" and maternal mortality in a tertiary hospital in Southern Nigeria: a retrospective study. Obstet Gynecol Int 2020. ID 3697637: 7 pages. https://doi. org/10.1155/2020/3697637

28. Chikadaya H, Madziyire MG, Munjanja SP. Incidence of maternal near miss in the public health sector of Harare, Zimbabwe: a prospective descriptive study. BMC Pregnancy Childbirth 2018 Nov 26;18(1):458. https://doi.org/10.1186/ s12884-018-2092-7

29. David E, Machungo F, Zanconato G, Cavaliere $E$, Fiosse S, Sululu C, et al. Maternal near miss and maternal deaths in Mozambique: a cross- sectional, region-wide study of 635 consecutive cases assisted in health facilities of Maputo province. BMC Pregnancy Childbirth 2014 Dec 10;14:401. https://doi.org/10.1186/s12884-0140401-3

30. Lotufo FA, Parpinelli MA, Haddad SM, Surita FG, Cecatti JG. Applying the new concept of maternal near-miss in an intensive care unit. Clinics (Sao Paulo) 2012; 67(3):225-30. https:// doi.org/10.6061/clinics/2012(03)04

31. Amin S, Ahmad J, Khan MS, Khan A, Khan RH, et al. Frequency of $\mathrm{ABO}, \mathrm{Rh}$ and $\mathrm{ABO}-\mathrm{Rh}$ blood groups in students of Gomal Medical College, D.I.Khan, Pakistan. Gomal J Med Sci 2020 JanMar; 18 (1):30-36. https://doi.org/10.46903/ gjms/18.01.2135

32. Saleem Z, Ullah I, Younis F, Khan N, Awan MSBF, Tauqir J, et al. Distribution of DR-TB by sex, age groups, occupation, province, division, district, type of disease, type of drug resistance, treatment regimen and outcome of treatment in DR-TB population in D.I.Khan Division, Pakistan. Gomal J Med Sci 2020 Jul-Sep; 18 (3):115-31. https:// doi.org/10.46903/gjms/18.03.897

33. Naqvi SWA, Saeed S, Rafique A, Saeed MH, Khan $\mathrm{N}$, Khan $\mathrm{A}$, et al. Prevalence and distribution of malaria by sex, age groups and species in year 2019 in suspected malarial population of district D.I.Khan, Pakistan. Gomal J Med Sci 2020 OctDec; 18(4):164-73.

\section{CONFLICT OF INTEREST \\ Authors declare no conflict of interest. GRANT SUPPORT AND FINANCIAL DISCLOSURE None declared.}

\section{AUTHORS' CONTRIBUTION}

The following authors have made substantial contributions to the manuscript as under:

Conception or Design:

Acquisition, Analysis or Interpretation of Data:

Manuscript Writing \& Approval:

SR, SY, NL

SR, SY, NL, GS

SR, SY, NL, GS

All the authors agree to be accountable for all aspects of the work in ensuring that questions related to the accuracy or integrity of any part of the work are appropriately investigated and resolved. 